\title{
Effect of Sisal Fiber Surface Treatment on Properties of Sisal Fiber Reinforced Polylactide Composites
}

\author{
Zhaoqian Li, ${ }^{1,2}$ Xiaodong Zhou, ${ }^{1}$ and Chonghua Pei ${ }^{2}$ \\ ${ }^{1}$ State Key Laboratory of Chemical Engineering, East China University of Science and Technology, Shanghai 200237, China \\ ${ }^{2}$ State Key Laboratory Cultivation Base for Nonmetal Composites and Functional Materials, Southwest University of Science \\ and Technology, Mianyang 621010, China
}

Correspondence should be addressed to Xiaodong Zhou,xdzhou@ecust.edu.cn and Chonghua Pei, peichonghua@swust.edu.cn

Received 30 March 2011; Accepted 10 June 2011

Academic Editor: James Njuguna

Copyright ( $) 2011$ Zhaoqian Li et al. This is an open access article distributed under the Creative Commons Attribution License, which permits unrestricted use, distribution, and reproduction in any medium, provided the original work is properly cited.

\begin{abstract}
Mechanical properties of composites are strongly influenced by the quality of the fiber/matrix interface. The objective of this study was to evaluate the mechanical properties of polylactide (PLA) composites as a function of modification of sisal fiber with two different macromolecular coupling agents. Sisal fiber reinforced polylactide composites were prepared by injection molding, and the properties of composites were studied by static/dynamic mechanical analysis (DMA). The results from mechanical testing revealed that surface-treated sisal fiber reinforced composite offered superior mechanical properties compared to untreated fiber reinforced polylactide composite, which indicated that better adhesion between sisal fiber and PLA matrix was achieved. Scanning electron microscopy (SEM) investigations also showed that surface modifications improved the adhesion of the sisal fiber/polylactide matrix.
\end{abstract}

\section{Introduction}

With the increasing of environmental protection consciousness, natural fibers as a group of environmental friendly reinforcements are in considerable demand in composites $[1,2]$. Natural fibers such as flax, hemp, sisal, nettle and jute were the most common reinforced elements $[2,3]$. Of course, natural fiber reinforced degradable polymers composite is likely more ecofriendly because that the reinforcement and the matrix (e.g., polylactide (PLA)) are readily biodegradable and such biocomposites are sometimes termed "green composites" $[4,5]$.

Natural fibers as reinforcement are familiar. However, there is also a major drawback associated with its application for reinforcement of polymeric matrices. The presence of hydroxyl and other polar groups in natural fibers constituents makes them exhibit high hydrophilic nature, which leads to incompatibility and poor wettability in a hydrophobic polymer matrix, and weak bonding in the fiber/matrix interface [6]. Herewith, there are many problems in dealing with the interface of natural fiber and polylactide.
Several approaches have been studied, such as surface modification of cellulose (e.g., esterification of cellulose and graft copolymerization onto cellulose substrates) and the use of some compatibilizers (e.g., maleated polylactide and isocyanate [7-11]). Nevertheless, only a limited number of studies had achieved good results. And there is no commercial sale of such interfacial compatibilizers in the market.

Among the various natural fibers, sisal fiber is fairly coarse and inflexible. It possesses moderately high specific strength and stiffness, durability, ability to stretch, and resistance to deterioration in saltwater $[12,13]$. Therefore, it can be used as a reinforcing material in polymeric resin matrices to make useful structural composite materials [14-16].

In our recent work, we have synthesized two different macromolecular coupling agents: MPS-g-PLA (Polylactidegraft- $\gamma$-methacryloxypropyltrimethoxysilane) and PLA-coPGMA (Polylactide-co- glycidyl methacrylate) [17, 18]. And the results of the former research suggested that they were efficient in modifying natural fiber surface and in improving the compatibility of PLA/cellulose composites. In this study, 


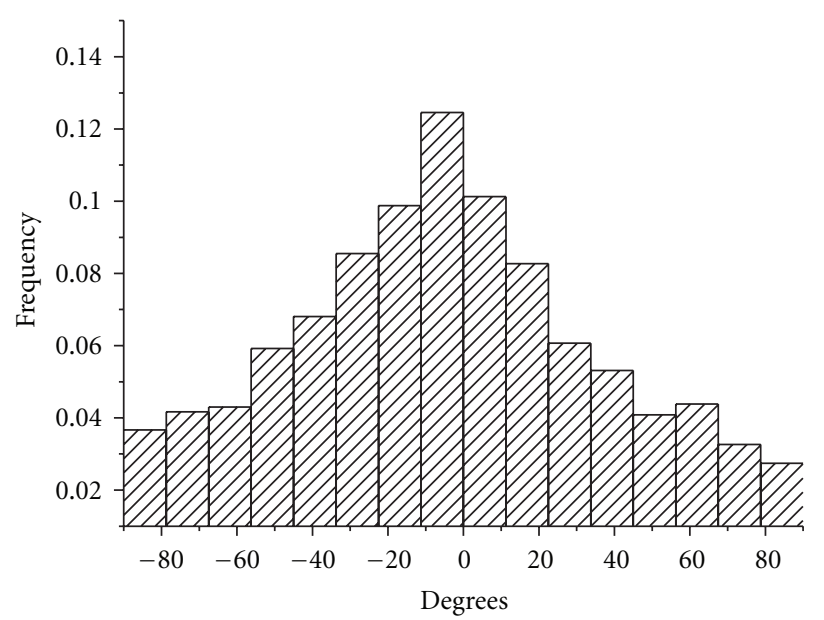

FIgURE 1: Fiber orientation distribution of PLA composite (PLA/sisal 30\%).

we attempt to use these two macromolecular coupling agents to improve the interfacial adhesion of PLA matrix and sisal fibers and solve the poor compatibility of natural fiber and PLA matrix. The effect of surface treatment of sisal fiber with MPS-g-PLA and PLA-co-PGMA on the mechanical properties was also evaluated.

\section{Experimental}

2.1. Materials. Commercial PLA (2002D, extrusion/thermoforming grade) from NatureWorks LLC was used in this work. It has a density of $1.24 \mathrm{~g} / \mathrm{cm}^{3}$, melt flow index of $5-7 \mathrm{~g} / 10 \mathrm{~min}\left(210^{\circ} \mathrm{C} / 2.16 \mathrm{Kg}\right)$. Before use, it was dried at $80^{\circ} \mathrm{C}$ under vacuum for $24 \mathrm{~h}$. Sisal fibers were supplied by Dongfang Sisal Group Co. Ltd., China. MPS-g-PLA and PLA-co-PGMA were prepared by us according to the literatures $[17,18]$.

2.2. Fiber Surface Modification. The MPS-g-PLA treatment of sisal fiber was carried out by immersing fibers in the dioxane solution of MPS-g-PLA at the concentration of $1 \mathrm{wt} \%$ for $48 \mathrm{~h}$ used acetic acid to adjust $\mathrm{pH}$. Sisal fibers were taken out of the solution and dried for 2 days at room temperature, then sisal fibers reacted with MPS-g-PLA at $120^{\circ} \mathrm{C}$ for $2 \mathrm{~h}$.

For PLA-co-PGMA treatment, sisal fibers were immersed in the dioxane solution of PLA-co-PGMA at the concentration of $1 \mathrm{wt} \%$ for $48 \mathrm{~h}$. After dried at room temperature, the products were Soxhlet extracted with THF for $24 \mathrm{~h}$ and then dried.

2.3. Fabrication of Composites. PLA and the treated sisal fibers were compounded with a twin screw extruder (selfmade, conical screw $110 \mathrm{~mm}$ in length), at $75 \mathrm{rpm}$ and $190^{\circ} \mathrm{C}$ for $10 \mathrm{~min}$. In order to obtain the desired specimens for various measurements and analysis, the molten composite samples were transferred, after extrusion through a preheated cylinder, to a mini-injection molder, which was preset

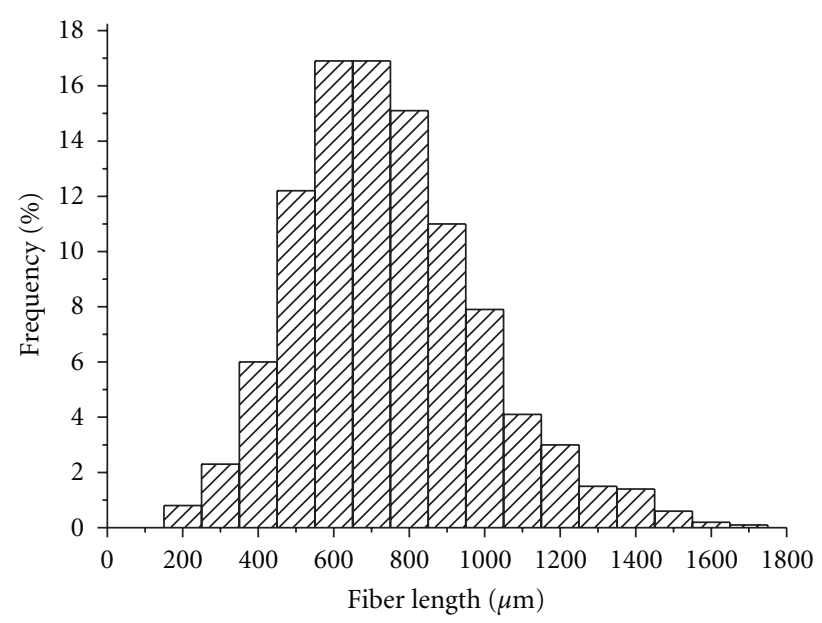

Figure 2: Fiber length distribution of PLA composite (sisal fiber content of $30 \%$ ).

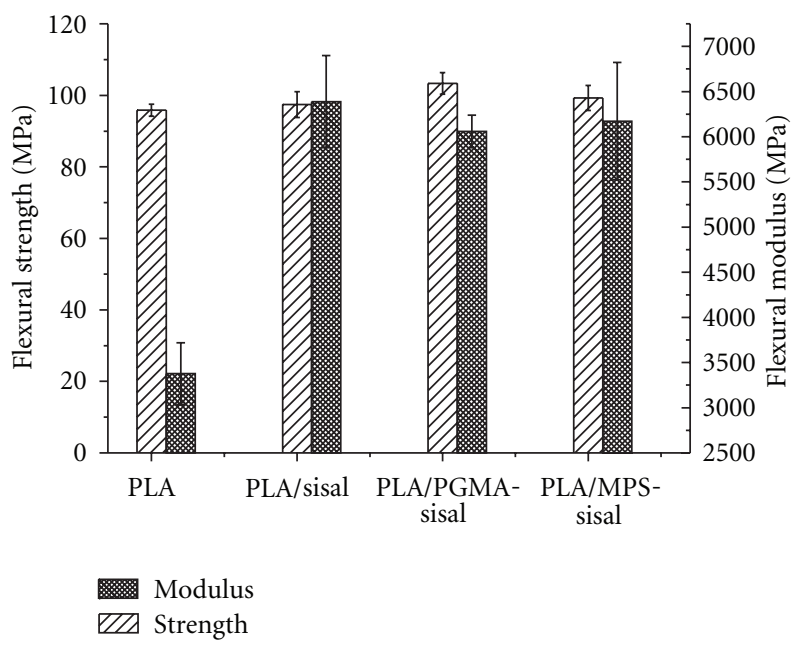

FIGURE 3: Flexural properties of 30 wt.\% surface-treated Sisal fibers compared to untreated Sisal fibers reinforced composites.

the desired temperature (injection temperature at $190^{\circ} \mathrm{C}$ ) and cooling system (mold temperature at $50^{\circ} \mathrm{C}$ ).

2.4. Mechanical Properties. The tensile properties of the composites were measured on a CMT4204 universal testing machine (Shenzhen SANS testing machine co., ltd., China) according to ASTM D630. The cross-head speed was $1 \mathrm{~mm} / \mathrm{min}$, and the gauge length was $30 \mathrm{~mm}$. The universal testing machine was also used to measure the flexural properties according to ASTM D790. The notched Izod impact strength was tested on an impact tester (Chengde, China), according to ASTM D256.

2.5. Dynamic Mechanical Analysis. The storage modulus, loss modulus, and loss factor (tan delta) of the composites were measured as a function of temperature (from 30 to $90^{\circ} \mathrm{C}$ ) using a TA Q800 DMA, equipped with a 


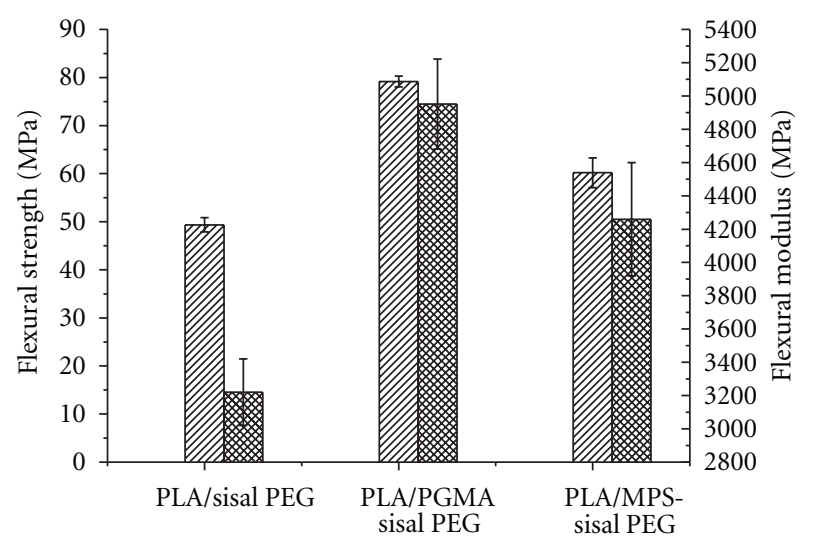

$\square D$ Strength

Figure 4: Flexural properties of PEG-Plasticized PLA and $30 \mathrm{wt} . \%$ sisal fiber composites.

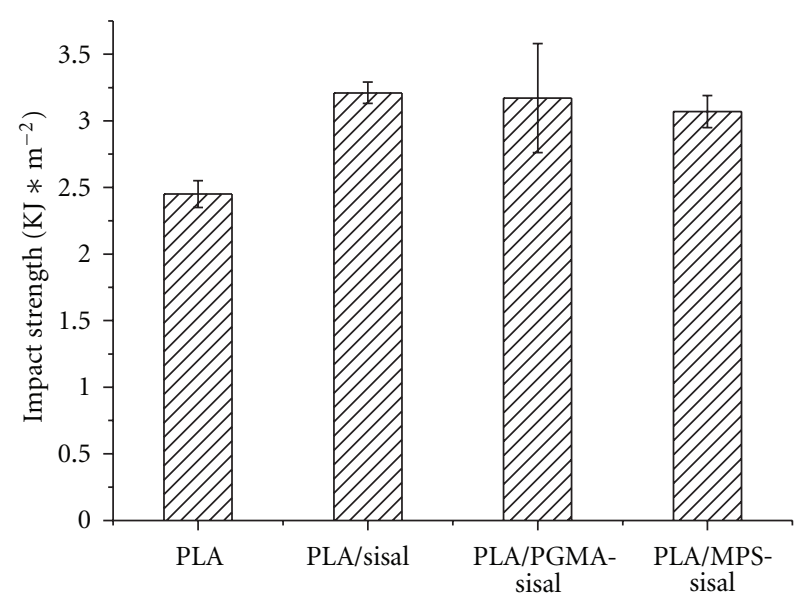

Figure 5: Notched Izod impact strength of Sisal fibers reinforced PLA composites.

dual-cantilever clamp at a frequency of $1 \mathrm{~Hz}$ and a heating constant rate of $3^{\circ} \mathrm{C} / \mathrm{min}$.

2.6. Scanning Electron Microscopy (SEM). Scanning electron microscopy (JSM-6360, FEI) was used to characterize the fractured surface of the composites. The samples were coated with a thin layer of gold before observation under the microscope mark, in order to increase the sample conductivity.

\section{Results and Discussion}

3.1. Fiber Orientation and Length Distribution. The fiber orientation and length distribution of the composites with unmodified sisal fiber is presented in Figures 1 and 2, respectively. The data were obtained from an analysis of a large number of micrographs. This composite shows a clear orientation with more than $30 \%$ of the fibers in the $\pm 20^{\circ}$ interval. In addition, the visible length distribution

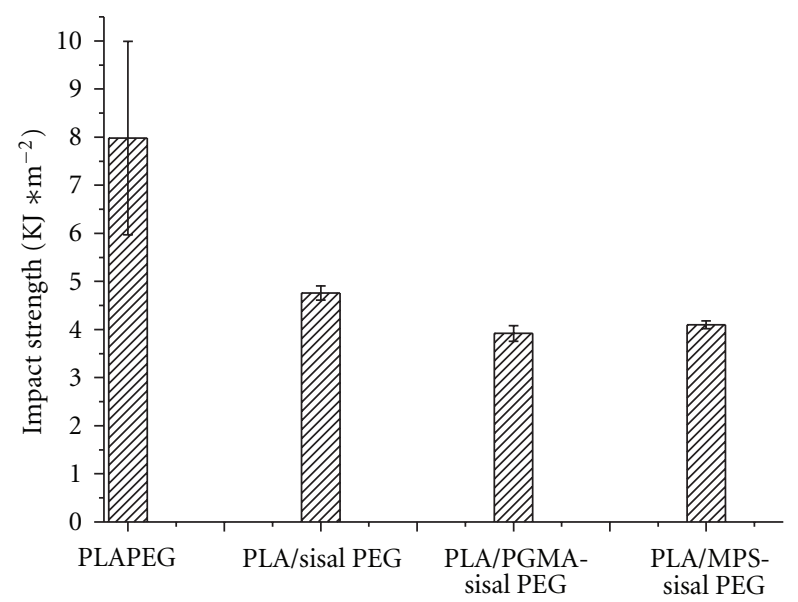

FIGURE 6: Notched Izod impact properties of PEG Plasticized PLA and their composites.

was measured from the micrographs, as shown in Figure 2. It was observed that most of the fibers had a length range of $600-800 \mu \mathrm{m}$, and the average fiber length was less than $1 \mathrm{~mm}$, as a result of the shear stress imposed on fibers during compounding in the twin screw extruder.

\subsection{Static Mechanical Properties}

3.2.1. Tensile Properties. Mechanical properties of composites were strongly determined by the fiber-matrix interface. The tensile strengths of sisal/PLA composites at maximum load were shown in Table 1. Compared to the composites made with untreated fibers, the tensile strengths of composites were an improvement of $6.77 \%$ for PLA-co-PGMA treated fibers and $5.35 \%$ for MPS-g-PLA-treated sisal fibers. This was an indication that surface modification promoted good wettability and better fiber-matrix adhesion, allowing efficient stress transfer between the matrix and the fibers. This could be due to the better dispersion of fibers and the interaction of PLA and modified sisal fibers, and the reaction mechanism of the coupling agents and natural fiber has been explained in former paper [17, 18].

Table 1 also showed the properties of PLA plasticized with PEG and their composites with sisal fibers. The tensile strength of PEG-plasticized PLA reduced 50\%, and the elongation at break was improved. In the treated fiber composites with PEG, the improvement of tensile strength was more obviously with respect to the samples without the plasticizer. This is likely because the increase of elongation at break optimizes the reinforcing effect of the fiber, and the interfacial adhesion play a key role in the transfer of the stress. Therefore, the results suggested that the surface treatment of sisal fibers significantly increased the interfacial adhesion.

3.2.2. Flexural Properties. Flexural properties of PLA and its composites were shown in Figure 3. According to the results, the introduction of sisal fibers significantly improved flexural modulus compared to the neat PLA matrix. The 


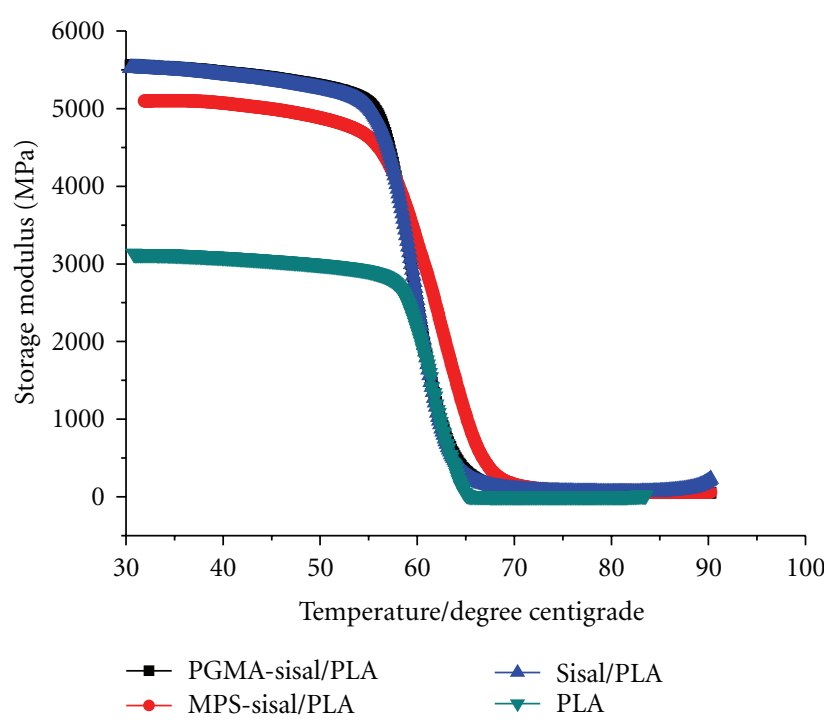

(a)

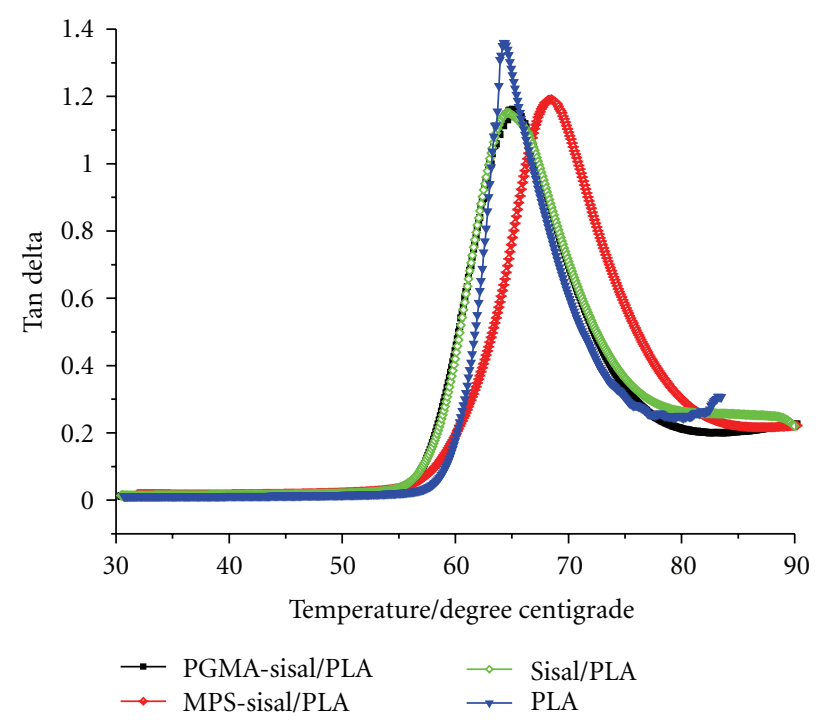

(b)

Figure 7: The storage modulus as a function of temperature for PLA and its composites. (a) Storage modulus; (b) The loss factor.

TABLE 1: Tensile properties of PLA and their composites with $30 \mathrm{wt} . \%$ sisal fibers.

\begin{tabular}{lcr}
\hline Sample & Tensile strength (MPa) & Improvement (\%) \\
\hline PLA & $56.97 \pm 1.25$ & - \\
PLA/sisal 30\% & $56.68 \pm 3.51$ & - \\
PLA/PLA-co-PGMA treatment sisal 30\% & $60.52 \pm 1.43$ & $6.23(6.77)$ \\
PLA/MPS-g-PLA treatment sisal 30\% & $59.71 \pm 1.57$ & $4.81(5.35)$ \\
PEG-plasticized PLA & $27.88 \pm 2.14$ & - \\
PEG-plasticized PLA/sisal 30\% & $33.96 \pm 2.17$ & 21.81 \\
PEG-plasticized PLA/PLA-co-PGMA treatment sisal 30\% & $39.08 \pm 1.48$ & 40.17 \\
PEG-plasticized PLA/MPS-g-PLA treatment sisal 30\% & $34.99 \pm 2.94$ & 25.50 \\
\hline
\end{tabular}

Note: the figure in brackets was compared with that of PLA/sisal $30 \%$.

two surface-treated sisal fibers composites improved the flexural strength compared to unmodified fibers. The best results were observed when the reinforcement surface had been treated with PLA-PGMA. This was due to improving the bonding between the fiber and the matrix. However, the flexural modulus of the PLA composites with the treated fibers decreases, which was paradoxical that good interfacial adhesion should improve the flexural modulus of composites. It is probable that the treatments have a lasting effect on natural fibers, such as the removal of amorphous components of fibers, especially on fiber stiffness $[19,20]$. All the treatments decreased the strength and modulus of sisal fibers and influenced the modulus of the composite.

Flexural properties of PEG-plasticized PLA composites were shown in Figure 4. It can be noticed that the surface modification of fiber caused marked changes in the flexural strength and modulus of the composites. This also indicates that surface treatment enhances the interfacial adhesion of fibers and matrix.

3.2.3. Impact Strength of Composites. The notched Izod impact strength of the surface-treated sisal fiber reinforced composite results can supply information of the fiber-matrix interactions. Figure 5 showed the impact strength of the untreated and surface-treated sisal fibers reinforced composites. The impact strength of surface-treated composites was higher than those of the PLA matrix. Surface-treated composites decreased slightly compared to the untreated fiber composite. The negative impact of the treated composites is attributed to the fact that the surface treatment improves the fiber-matrix adhesion, which leads to the fracture of fibers rather than their pullout when they receive a mechanical shock.

The impact strength for PEG-plasticized PLA and their composites were shown in Figure 6. The same tendency is seen there. That is, surface modification reduces the impact strength of composites, which is in agreement with the report made by Huda et al. [21].

3.3. Dynamic Mechanical Analysis. Figure 7 showed the temperature dependence of dynamic storage modulus and tan delta of the PLA and its composites. As seen in Figure 7(a), the storage modulus increased with the addition of sisal 


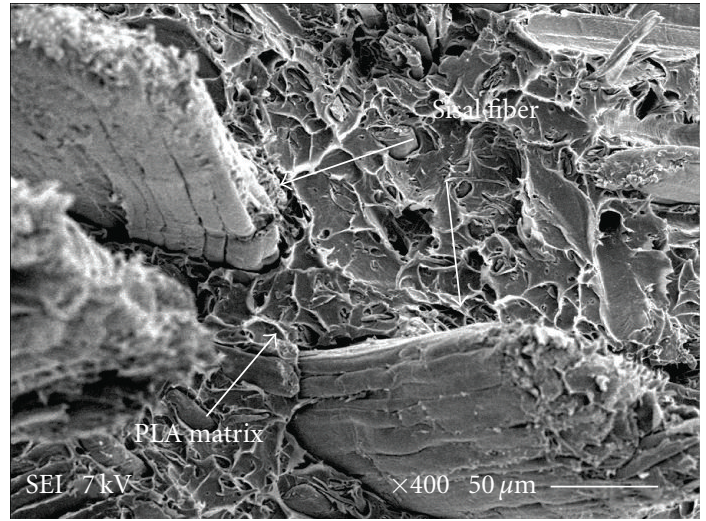

(a)

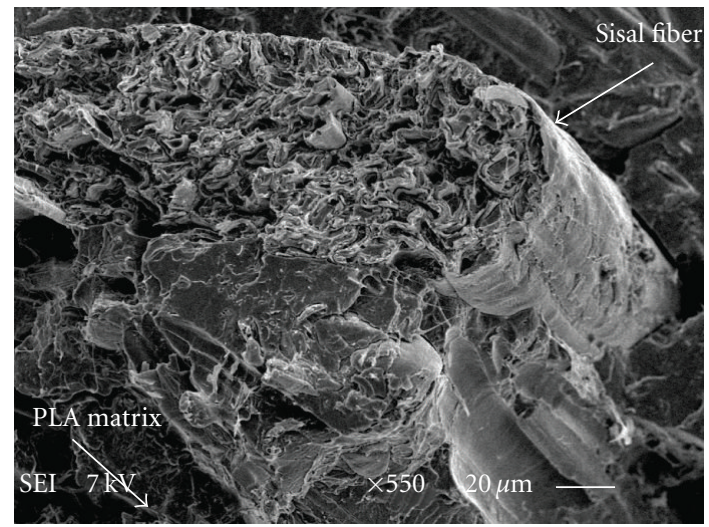

(c)

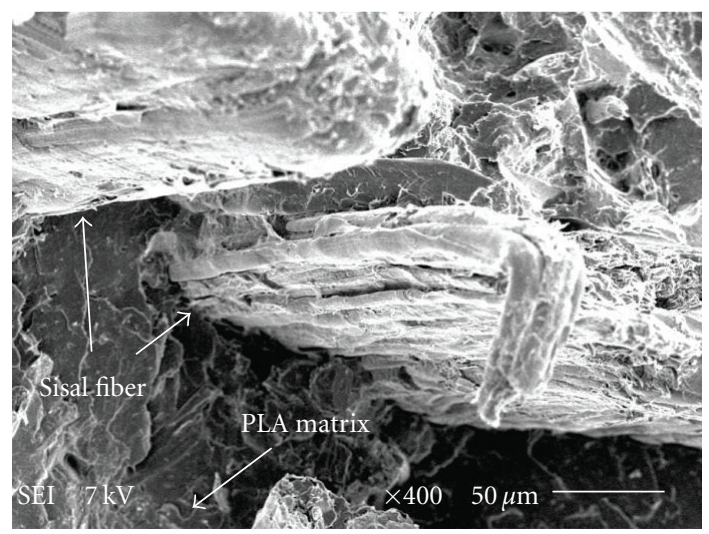

(e)

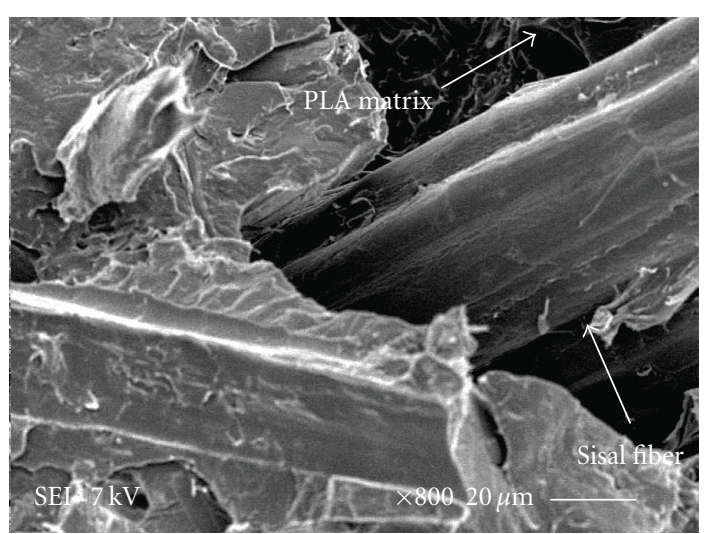

(b)

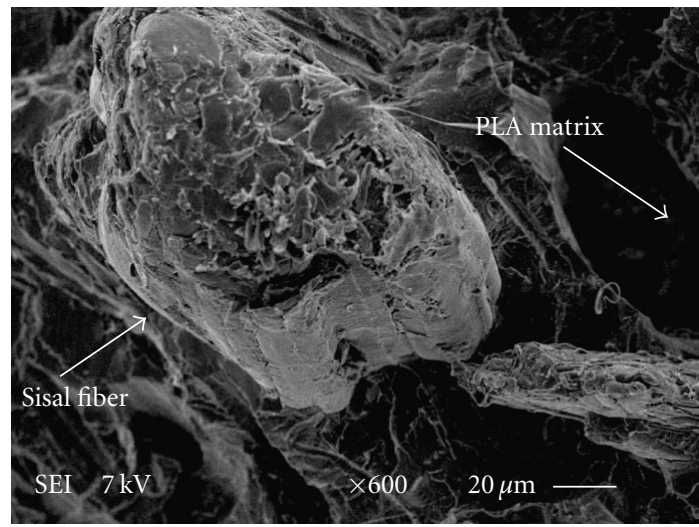

(d)

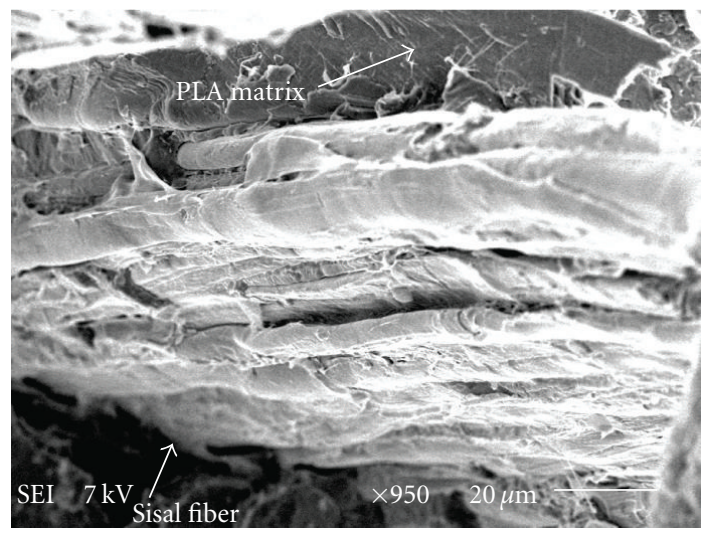

(f)

Figure 8: Morphology of a fractured surface of 30 wt.\% sisal fiber/PLA composites. (a, b) Unmodified sisal fiber; (c, d) sisal fiber modified with PLA-co-PGMA; (e, f) sisal fiber modified with MPS-g-PLA.

fibers compared to that of PLA, which indicated that stress could be effectively transferred from the matrix to the fiber. The effect of surface treatment on the storage modulus of composites can be observed by comparing sisal/PLA with MPS-Sisal/PLA and PLGA-Sisal/PLA. Compared to unmodified fiber, the storage modulus of composites has a slight increase with PLA-co-PGMA treatment and a decline with MPS-g-PLA treatment. The chemical treatment of sisal fibers will bring about a positive effect as well as a negative one upon properties of fibers. Surface treatments of sisal fiber decreased its surface energy and the interfacial tension of fibers/PLA, which improved the dispersion of sisal fiber in PLA matrix and the compatibility of fiber and PLA $[17,18]$. On the other hand, the strength and modulus of natural fiber reduced because of chemical treatment. When the two effects considered together, the modulus of PLA composites didn't get a significant rise, which was accorded with the result of flexural properties of the composites. 
As can be seen in Figure 7(b), the addition of sisal fiber made the loss factor of PLA matrix diminish, which resulted from the impeding of sisal fibers on the movement of PLA molecular chain. The treatment with MPS-g-PLA enhanced the glass transition temperature of the composite. There was relatively little difference in their peak value of the loss factor of composites, which indicated that the composites possessed similar damping properties. The $\tan \delta$ of composites with MPS-g-PLA treatment was high compared to unmodified fiber, which agreed with Sreekumar et al.'s research result, and they thought this was for the decrease of the compactness and rigidity of natural fiber after the treatment [22]. Other researchers suggested that the increase of loss factor attributed to well-interfacial adhesion, which limited the movement of polymer molecular chains and increased the molecular segmental friction [23].

3.4. Morphology of Fractured Surface. SEM micrographs of the fractured surface of the treated and untreated sisal fiber composites can be seen in Figure 8. Figures $8(\mathrm{a})$ and 8 (b) showed that no PLA matrix adhered to the fibers which were pulled out to a large extent. The fiber pullout in micrographs was an indication of weak fiber/matrix adhesion. In Figures $8(\mathrm{c}), 8(\mathrm{~d}), 8(\mathrm{e})$, and $8(\mathrm{f})$, it was noted that sisal fibers were tightly connected with PLA matrix, which suggested interfacial bonding between sisal fiber and PLA was improved by the treatment with coupling agent. This indicated the improvement in the adhesion between fiber surface, and matrix and this well adhesion also led to an increase in mechanical properties. Therefore, surface modification has improved the compatibility of sisal fiber/PLA.

\section{Conclusions}

This study demonstrated that surface modification of sisal fiber had slightly increased tensile strength of composites and decreased its impact strength, which suggested that surface treatment improved the compatibility of sisal fiber and PLA matrix and effective stress transferred between fibers and matrix. In the case of PEG-plasticized polylactide, surface modification of sisal fiber made efficiency of reinforcement more obvious. This further revealed the interfacial binding strength of PLA, and fiber with PLA-co-PGMA and MPSg-PLA was higher compared to unmodified fiber. From the DMA results, the storage modulus of composites has a slight increase with PLA-co-PGMA treatment and a decline with MPS-g-PLA treatment in contrast with that of unmodified fiber/PLA composites. SEM micrographs of the fracture surface of the impact specimen indicated that the adhesion between fiber and matrix could be improved after surface treatment of sisal fiber with coupling agents.

\section{Acknowledgment}

The authors acknowledge the financial support of the Open Project Program of the State Key Laboratory of Chemical Engineering, East China, University of Science and Technology.

\section{References}

[1] A. K. Bledzki, W. Zhang, and A. Chate, "Natural-fibrereinforced polyurethane microfoams," Composites Science and Technology, vol. 61, no. 16, pp. 2405-2411, 2001.

[2] A. Ashori, "Wood-plastic composites as promising greencomposites for automotive industries!" Bioresource Technology, vol. 99, no. 11, pp. 4661-4667, 2008.

[3] J. Ganster and H.-P. Fink, "Novel cellulose fibre reinforced thermoplastic materials," Cellulose, vol. 13, no. 3, pp. 271-280, 2006.

[4] M. S. Huda, A. K. Mohanty, L. T. Drzal, E. Schut, and M. Misra, “'Green' composites from recycled cellulose and poly(lactic acid): physico-mechanical and morphological properties evaluation," Journal of Materials Science, vol. 40, no. 16, pp. 4221-4229, 2005.

[5] A. Iwatake, M. Nogi, and H. Yano, "Cellulose nanofiberreinforced polylactic acid," Composites Science and Technology, vol. 68, no. 9, pp. 2103-2106, 2008.

[6] X. Li, L. G. Tabil, and S. Panigrahi, "Chemical treatments of natural fiber for use in natural fiber-reinforced composites: a review," Journal of Polymers and the Environment, vol. 15, no. 1, pp. 25-33, 2007.

[7] H. Lönnberg, Q. Zhou, H. Brumer III, T. T. Teeri, E. Malmström, and A. Hult, "Grafting of cellulose fibers with $\operatorname{poly}(\varepsilon$-caprolactone) and poly(L-lactic acid) via ring-opening polymerization," Biomacromolecules, vol. 7, no. 7, pp. 21782185, 2006.

[8] M. Takatani, K. Ikeda, K. Sakamoto, and T. Okamoto, "Cellulose esters as compatibilizers in wood/poly(lactic acid) composite," Journal of Wood Science, vol. 54, no. 1, pp. 54-61, 2008.

[9] N. Teramoto, K. Urata, K. Ozawa, and M. Shibata, "Biodegradation of aliphatic polyester composites reinforced by abaca fiber," Polymer Degradation and Stability, vol. 86, no. 3, pp. 401-409, 2004.

[10] D. Plackett, "Maleated polylactide as an interfacial compatibilizer in biocomposites," Journal of Polymers and the Environment, vol. 12, no. 3, pp. 131-138, 2004.

[11] S. H. Lee and S. Wang, "Biodegradable polymers/bamboo fiber biocomposite with bio-based coupling agent," Composites Part A, vol. 37, no. 1, pp. 80-91, 2006.

[12] S. M. Sapuan, M. Harimi, and M. A. Maleque, "Mechanical properties of epoxy/coconut shell filler particle composites," Arabian Journal for Science and Engineering, vol. 28, no. 2B, pp. 171-181, 2003.

[13] P. V. Joseph, K. Joseph, and S. Thomas, "Effect of processing variables on the mechanical properties of sisal-fiber-reinforced polypropylene composites," Composites Science and Technology, vol. 59, no. 11, pp. 1625-1640, 1999.

[14] F. A. Silva, D. Zhu, B. Mobasher, C. Soranakom, and R. D. Toledo Filho, "High speed tensile behavior of sisal fiber cement composites," Materials Science and Engineering A, vol. 527, no. 3, pp. 544-552, 2010.

[15] J. T. Kim and A. N. Netravali, "Mercerization of sisal fibers: effect of tension on mechanical properties of sisal fiber and fiber-reinforced composites," Composites Part A, vol. 41, no. 9, pp. 1245-1252, 2010.

[16] I. Singh, P. K. Bajpai, D. Malik, A. K. Sharma, and P. Kumar, "Feasibility Study on Microwave Joining of 'green composites," Akademeia, vol. 1, no. 1, pp. 1-6, 2011.

[17] Z. Li, X. Zhou, and C. Pei, "Synthesis and characterization of mps-g-pla copolymer and its application in surface modification of bacterial cellulose," International Journal of Polymer 
Analysis and Characterization, vol. 15, no. 4, pp. 199-209, 2010.

[18] Z. Q. Li, X. D. Zhou, and C. H. Pei, "Synthesis of PLAco-PGMA copolymer and its application in the surface modification of bacterial cellulose," International Journal of Polymeric Materials, vol. 59, no. 9, pp. 725-737, 2010.

[19] M. Z. Rong, M. Q. Zhang, Y. Liu, G. C. Yang, and H. M. Zeng, "The effect of fiber treatment on the mechanical properties of unidirectional sisal-reinforced epoxy composites," Composites Science and Technology, vol. 61, no. 10, pp. 1437-1447, 2001.

[20] M. S. Huda, L. T. Drzal, A. K. Mohanty, and M. Misra, "Effect of chemical modifications of the pineapple leaf fiber surfaces on the interfacial and mechanical properties of laminated biocomposites," Composite Interfaces, vol. 15, no. 2-3, pp. 169191, 2008.

[21] M. S. Huda, L. T. Drzal, A. K. Mohanty, and M. Misra, "Effect of fiber surface-treatments on the properties of laminated biocomposites from poly(lactic acid) (PLA) and kenaf fibers," Composites Science and Technology, vol. 68, no. 2, pp. 424-432, 2008.

[22] P. A. Sreekumar, R. Saiah, J. M. Saiter et al., "Effect of chemical treatment on dynamic mechanical properties of sisal fiberreinforced polyester composites fabricated by resin transfer molding," Composite Interfaces, vol. 15, no. 2-3, pp. 263-279, 2008.

[23] I. C. Finegan and R. F. Gibson, "Recent research on enhancement of damping in polymer composites," Composite Structures, vol. 44, no. 2-3, pp. 89-98, 1999. 

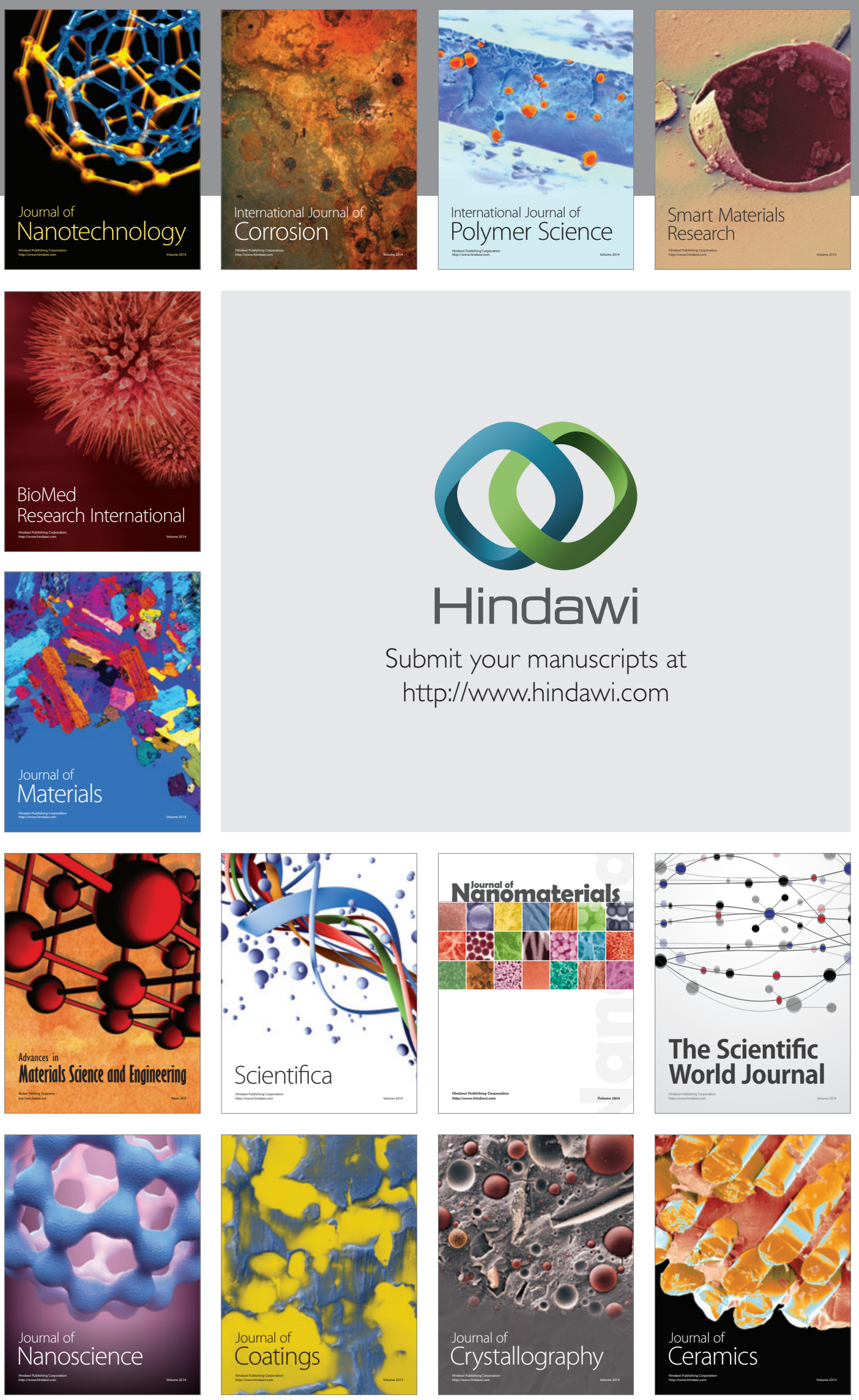

The Scientific World Journal

Submit your manuscripts at

http://www.hindawi.com

\section{World Journal}

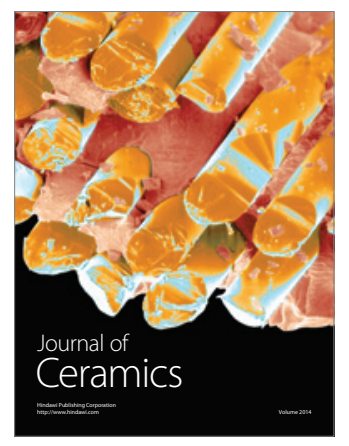

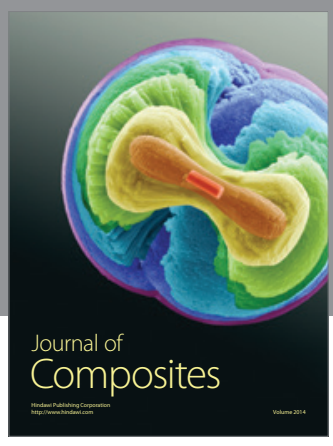
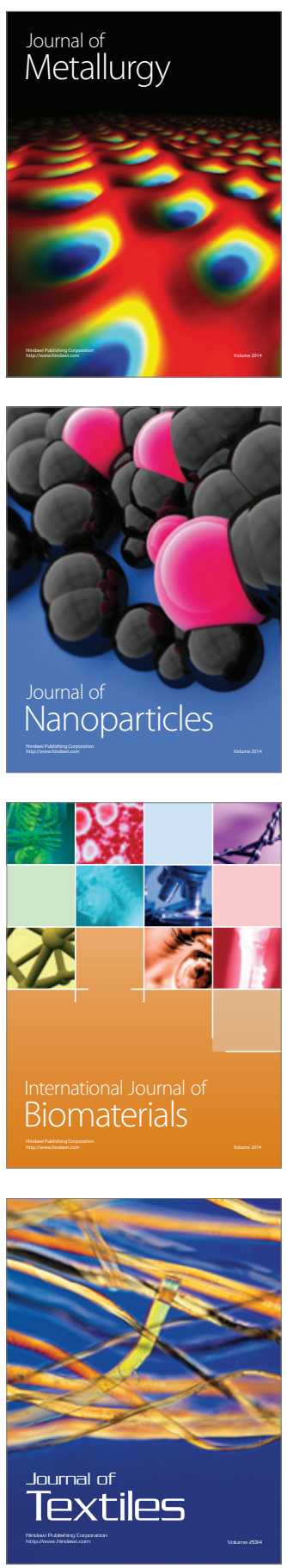